\title{
THE DOMESTIC GENERAL DEVELOPMENT OF PEOPLE'S REPUBLIC OF CHINA (PRC)
}

\author{
Mario Arturo Ruiz Estrada and Emile Kok-Kheng Yeoh
}

This research paper presents a new analytical model to study the evolution of the general development process of People's Republic of China (PRC) from a new perspective of analysis. This new analytical model is called the Domestic General Development Model (DGD-Model). The DGD-Model is not intended to use a forecasting model in any case. However, its application is not limited to the study of a special group of countries. It is not constrained by issues about the region or countries that are interested in apply DGD-Model.

Faster economic growth and trade of PRC is not a purely economic phenomenon but a multidimensional phenomenon. I evaluate the prospects of two large parts of East China (coastal) ${ }^{1}$ (coastal) and West China (inland) $)^{2}$ (inland) from a multidimensional perspective encompassing the political, social, economic and technological dimensions. To do so, I use the Domestic General Development Model (DGD-Model) based on GDRIModel by Mario A Ruiz Estrada in 2004. The main finding of this research is that there is a wide and growing gap between East and West China (inland) in terms of political, social, economic and technological development as well as overall development.

\section{Introduction}

This paper introduces a new analytical model of analysis to monitoring the development process from a general perspective. It is called Domestic General Development Model (DGD-Model). It is based on the application of a group of new indicators and graphs. The new group of indices and graphs can show the evolution and stages of the development process of any country from a General perspective.

The difference between the DGD-Model and other analytical models, such as the human development report is that DGD-Model presents a General understanding in the study of development process from economic, political, social and technological views simultaneously. The objective of the DGD-Model is to offer to policy-makers and researchers a new alternative analytical toolbox for studying the results achieved with any country into its development process analysis.

\section{The Domestic General Development Model (DGD-Model)}

The DGD-Model is a measuring model for studying development process from a General perspective. The proposed DGD-Model is a simple and flexible analytical model. It applies dynamic and general equilibrium analysis to show the past and present situations in the development process of any country based on a toolbox of new indices

\footnotetext{
1 Dalian, Beijing, Jinan, Shanghai, Hangzhou, Fuzhou, Guangzjou, Honk Kong, Taiwan, Macau and Hainan.

2 Yi'an, Lanzhou, Kunning, Hohhot, Urimqui, Lhasa, Chengdu, Xi' an, Kashi and Guiyang.
} 
and graphs. Its field application is not constrained by country development stage, such as, developed country, developing country and less developed countries (LDC's).

The application of the DGD-Model is considered the characteristics, conditions and historical moments of any country development stage. The DGD-Model is like a simulator that applies a series of simulations in different scenarios and in different phases of the development process of any country. This model does not attempt in any case to be a forecasting model. It focuses on the past and present situation of any country into its development process as a whole.

\section{The Domestic General Development Model (Dgd-Model) Assumptions}

This part of the research presents the assumptions is used by the Domestic General Development Model (DGD-Model). DGD-Model consists in all economic, technological, political and social characteristics that any country can show in its different phases of its development. DGD-Model assumes that each country has its own domestic system development (DSD). The DSD is based on three basic assumptions are:

1. Change of Domestic System Development (DSD) in any country cannot be forced; it can only be induced by material incentives and motivation

2. The Domestic System Development (DSD) of any country is spurred by the limitation of resources

3. Each Domestic System Development (DSD) has its unique characteristics.

Therefore it might be difficult to try to implement a successful Domestic System

Development (DSD) in another less successful Domestic System Development (DSD)

The Domestic System Development (DSD) analysis concept offers a new perspective of analysis and research in the field of development. The traditional research is based on economic, political, social and technological point of view; but with DSD analysis, it is possible to visualize different countries' developments from a General perspective. ${ }^{3}$

\section{Phases in the Domestic General Development Model (DGD-Model)}

\section{Phase I: Design of the Multi-input Database Table}

The multi-input database table is a new style of analysis framework that permits storage of large amount of data to measure a single variable. This single variable can show the evolution of any phenomenon from a General perspective. The multi-input database table is designed to evaluate either by country or region.

The first type of multi-input database table pertains to "country or domestic system development". It uses " $\mathrm{N}$ " number of variables. The number ' $\mathrm{N}$ ' is decided by the researchers or policy-makers. The number of cases in the study is represented by " $\mathrm{M}$ ". In the case of DGD-Stage, " $\mathrm{M}$ " represents only one country (Domestic System Development -DSD-). The time factor " $\mathrm{T}$ " is dependant on the time parameters that the researchers or policy-makers are interested in using. Therefore, " $\mathrm{T}$ " can be in terms of years or decades.

The second type of multi-input database table pertains to "many countries or Domestic System Developments DSD's". All the conditions and functions of "N", "M"

3 Mario A Ruiz Estrada, "The General Dimension of Regional Integration (GDRI)", FEA 2004-7, Faculty of Economics and Administration Working Papers, University of Malaya,2004, pp. 1-42. 
and " $\mathrm{T}$ " factors are the same as that in the first type of multi-input database table, except that " $\mathrm{M}$ " here represents a "different countries or domestic system developments" rather than a "countries". For this research paper, this second type of multi-input database (by country) is adopted. ${ }^{4}$

\section{Phase II: Measurement of Domestic Development Indices (Xi)}

The second phase of the implementation of the DGD-Model involves the measurement of Domestic Development Indices $\left(X_{i}\right)$ using the variables in four basic multi-input database tables. The Domestic General Development Indices are Domestic Political Development Index $\left(X_{1}\right)^{5}$, Domestic Social Development Index $\left(X_{2}\right)^{6}$, Domestic Economic Development Index $\left(X_{3}\right)^{7}$ and Domestic Technological Development Index $\left(X_{4}\right)^{8}$. These variables are analyzed with their codes, descriptions and parameters respectively (See table $3,4,5,6,7,8,9,10,11,1213$ and 14).

\section{Rational Selection of Sub-variables in each Multi-input Database Table}

\section{Regional Political Development}

The regional political development is divided in two large sections: external factors and internal factors.

The External Factors

Colonization: The model assumes that countries which here colonized for a long time or continue under the hegemony center domination can stop the process of regional integration anywhere.

4 Mario A Ruiz Estrada, "The Trade Liberalization Evaluation (TLE) Methodology", Journal of Policy Modeling, Vol.26, No.8-9, 2004 (a), pp. 1015-1029.

5 The measuring of Domestic Political Development Index $\left(X_{1}\right)$ originates from the calculus obtained from the politics multi-input database table, see table 3). After we obtain the result of $X_{1}$, we can proceed to classify our results into three different parameters. These parameters are under-developed stage or level $1\left(0 \leq X_{1} \leq 0.33\right), X_{1}$ index is developing stage or level 2 $\left(0.34 \leq X_{1} \leq 0.66\right)$ and $X_{1}$ index is developed stage or level $3\left(0.67 \leq X_{1} \leq 1\right)$.

6 The measuring of Domestic Social Development Index $\left(X_{2}\right)$ originates from the calculus applied in the social multi-input database table (see table 6). After we obtain the result of $X_{2^{\prime}}$ we can proceed to classify our results into three different parameters. These parameters are under-developed stage or level $1\left(0 \leq X_{2} \leq 0.33\right), X_{2}$ index is developing stage or level 2 (0.34 $\left.\leq X_{2} \leq 0.66\right)$ and $X_{2}$ index is developed stage or level $3\left(0.67 \leq X_{2} \leq 1\right)$.

7 The measuring of Domestic Economic Development Index $\left(\mathrm{X}_{3}\right)$ originates from the calculus applied in the economic multi-input database table (see table 9). After we obtain the result of $X_{3}$, we can proceed to classify our results into three different parameters. These parameters are under-developed stage or level $1\left(0 \leq X_{3} \leq 0.33\right), X_{3}$ index is developing stage or level 2 $\left(0.34 \leq X_{3} \leq 0.66\right)$ and $X_{3}$ index is developed stage or level $3\left(0.67 \leq X_{3} \leq 1\right)$.

8 The measuring of Domestic Technological Development Index $\left(\mathrm{X}_{4}\right)$ originates from the calculus applied in the technological multi-input database table (see table 12). After we obtain the result of $X_{4^{\prime}}$ we can proceed to classify our results into three different parameters. These parameters are under-developed stage or level $1\left(0 \leq X_{4} \leq 0.33\right), X_{4}$ index is developing stage or level $2\left(0.34 \leq X_{4} \leq 0.66\right)$ and $X_{4}$ index is developed stage or level $3\left(0.67 \leq X_{4} \leq 1\right)$. 
Group negotiation power: This can be visualized by the constant number of meetings try to merge all members into a single region.

Foreign Policy Orientation in each Member: The foreign policy is divided into two large focuses under regional and global level (world).

Negotiation Style: This sub-variable can show the style of negotiation under individual or grouping behavior.

The Internal Factors

International Organization Support: The international organizations can facilitate financial and technical support.

Intra-regional institutions number: The number of institutions can play an important role in the development of regional integration process.

Political regime: This sub-variable can offer political stability in the region.

Legislative background: This can help to facilitate the regional legal framework environmental.

Internal Security: Security for local and regional citizens.

Human Rights: The level of protection of human rights in each member in the same region.

Border Problems: If there are border problems then this problem can stop regional integration process.

Political Stability: This is a basic condition to integrate all countries into the same region

Public Administration: Good public administration can facilitate regional integration process management.

Army size: Less spending on army services can help to allocate resources on social public services.

Bureaucracy level: Large bureaucracy can generate difficulties in the regional integration process.

Regional Social Development

The regional social development is formed by seven sub-variables:

Literacy: This sub-variable can show the human capital stock under regional level.

Social Problems: These can generate instability in one member country or regional level. 
Health and Medical programs: The social welfare orientation of the region.

External Culture Influence: Society behavior to become an individual or a collective society.

Food Security: Prevents regional disasters and emergencies.

Public Education: Infrastructure for training and high education at the regional level.

Low Cost Housing Projects: The equity in the distribution of income under regional level.

\section{Regional Economic Development}

The regional economic development is formed by eight large sections which are production consumption, trade, labor, investment, infrastructure, government and international cooperation.

\section{a) Production}

The eleven sub-variables are considered in this section. Among the eleven variables, we include the study of the GDP to observe the production structure and growth. In the same item is considered natural resources, oil production and environmental protection to detect the supply of resources for the regional production. Market location, industrial concentration and subsidies level can generate distortions in regional prices. Export structure can help to visualize if there exist similarities in the export products that members in the same region offer to the international market. The copyright of patents and marks can play an important role in the control of pirated massive production.

\section{b) Consumption}

In the consumption section seven sub-variables are considered. It considers income per-capita, buyer purchase, poverty level, saving rate, inflation rate and wealth distribution. All these sub-variables need to be found among all members to determine the consumption behavior under the regional level. The market size can play important role in the regional integration process can help to join small markets into a single market.

\section{c) Trade}

The trade section has five sub-variables. All these variables will show the behavior of the external sector under the regional level and the possible obstacles that each member or the region may have. These variables are intra-regional trade volume, extra-regional trade volume, intra regional tariff application, openness and monopoly controls.

\section{d) Labor}

The labor section is formed by six sub-variables. This section considers that international social division can facilitate the regional integration process together with labor distribution under urban and rural area. The immigration and emigration levels can show the mobility of labor into the region and the rest of the world. The population 
growth is considered a vital variable in the study of labor to observe the population pyramid of the region and future human capital stock supply. The labor productivity also plays an important role to observe the possibility of FDI attraction to expand regional production and exports.

\section{e) Investment}

This section is divided into seven sub-variables. Three categories of investment, which there are domestic, intra-regional and foreign direct investment (FDI) is used in this section. We are interested to study how these three types of investment play an important role in the regional integration process of any region. Additionally, the same section considers that the privatization process (public goods) needs to be considered in the analysis of regional integration process to facilitate the mobility of capital at the regional and international level. The interest rate, exchange rate stability and stock market activity can show the level of banking and stock market development in the region, and the possibility to of joining the financial regional system.

\section{f) Infrastructure}

The infrastructure is formed by six sub-variables and this section will show the level of physical infrastructure under the regional level, and how it can facilitate in the mobility of labor and goods (transport system, intra-regional physical projects and tourism), communication services (telecommunications) and energy (electricity production).

\section{g) Government}

The government section has seven sub-variables. The inclusion of this section into the analysis of regional economic development is to study the tax income distribution (taxation), domestic debt and foreign debt of each member in the same region. In the same issue, it is possible to observe the level of government income and spending (e.g. government expenditures and planning economy sub-variables) of the different governments in the same region. We assume that good performance of governments can help the standardization and management of public finances (income and spend). Additionally, in the same study we include the level of corruption. This can help to observe how corruption can affect the regional integration process originated by political groups to protect its personal interests.

\section{Regional Technological Development}

The regional technological development is formed by ten sub-variables. This section aims to show the level of technological development of each member in the same region. We assume that if majority of members in the same region have a small gap of technological development this can facilitate the regional integration process. The variables are technology (R\&D) level, internet hosts, software production, internet access, telecommunications, research institutes, biotechnology advances, Import of new technologies, R\&D public investment and IT development. 


\section{Types of Multi-input Data Base Table}

The first type of multi-input database table pertains to "country or domestic system development". It uses " $\mathrm{N}$ " number of variables. The number ' $\mathrm{N}$ ' is decided by researchers or policy-makers. The number of cases in the study is represented by " $\mathrm{M}$ ". In the case of RIE-Methodology, " $\mathrm{M}$ " represents only one country (domestic system development). The time factor " $\mathrm{T}$ " is dependant on the time parameters that the researchers or policy-makers are interested in using. Therefore, " $\mathrm{T}$ " can be in terms of years or decades. The second type of multi-input database table pertains to "region or regional system development". All the conditions and functions of " $\mathrm{N}$ ", " $\mathrm{M}$ " and " $\mathrm{T}$ " factors are the same as that in the first type of multi-input database table, except that " $\mathrm{M}$ " here represents a "region or regional system development" rather than a "country or domestic system development". For this chapter, the second type of multi-input database (by region) is adopted.

TABLE 3

MULTI-INPUT DATABASE TABLE: REGIONAL GLOBAL POLITICAL DEVELOPMENT OF TRADE BLOC "XYZ"

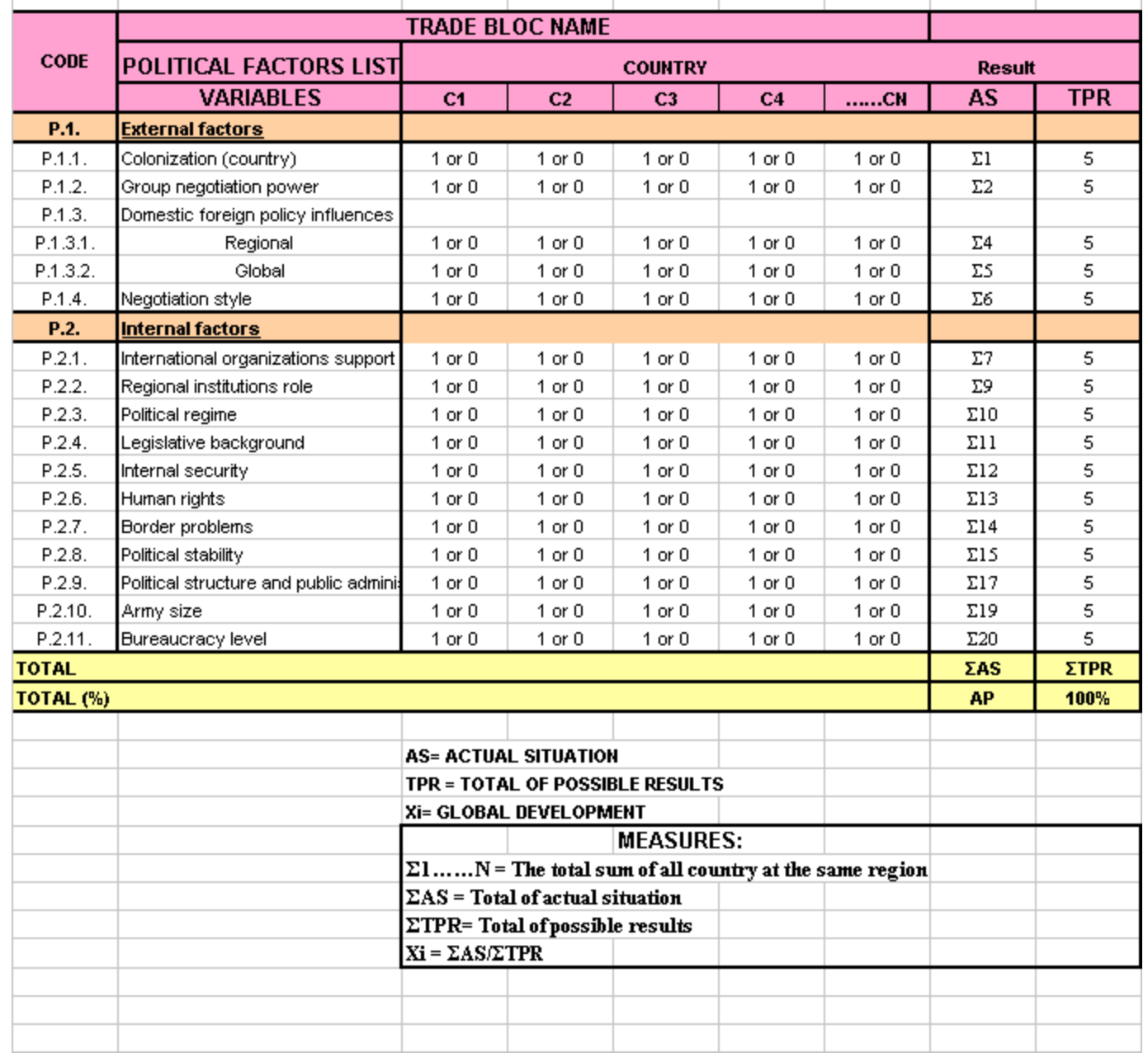


TABLE 4

THE GLOBAL REGIONAL POLITICAL DEVELOPMENT PARAMETERS

\begin{tabular}{|c|c|c|c|c|c|}
\hline P.1. & External factors & Limit & \multicolumn{3}{|c|}{ Description } \\
\hline P.1.1. & Colonization (country) & $1=$ Exist or $0=N E$ & \multicolumn{3}{|c|}{ Short colonization period less than 50 years } \\
\hline P.1.3.1. & Regional & $1=\mathrm{H}$ or $0=\mathrm{L}$ & \multicolumn{2}{|c|}{ Foreign affairs policy attention focus } & \\
\hline P.1.3.2. & Global & $1=\mathrm{H}$ or $0=\mathrm{L}$ & \multicolumn{2}{|c|}{ Foreign affairs policy attention focus } & \\
\hline P.1.4. & Negotiation style & $1=\mathrm{F}$ or $0=1$ & \multicolumn{2}{|c|}{ Procedures of style negotiations } & \\
\hline P.2. & Internal factors & Limit & \multicolumn{3}{|c|}{ Source } \\
\hline P.2.4. & Legislative background & $1=\mathrm{E}$ or $0=\mathrm{NE}$ & Law system exist & & \\
\hline P.2.5. & Internal security & $1=\mathrm{H}$ or $0=\mathrm{L}$ & \multicolumn{3}{|c|}{ Most safe 100 countries around the world } \\
\hline P.2.6. & Human rights & $1=\mathrm{H}$ or $0=\mathrm{L}$ & \multicolumn{3}{|c|}{ Human rights first 150 countries around the world } \\
\hline P.2.7. & Border problems & $1=$ Ne or $0=E$ & \multicolumn{2}{|c|}{ Border problems at the last 30 years } & \\
\hline P.2.8. & Political stability & $1=\mathrm{H}$ or $0=\mathrm{L}$ & \multicolumn{3}{|c|}{ Exist democratic elections at the last 20 years } \\
\hline P.2.9. & Public administration & $1=\mathrm{F}$ or $0=\mathrm{U}$ & \multicolumn{2}{|c|}{ Based on taxation system structure } & \\
\hline P.2.10. & Army size & $1=\mathrm{L}$ or $\mathrm{H}=0$ & \multicolumn{3}{|c|}{ Less of the $10 \%$ of all population in this country } \\
\hline P.2.11. & Bureaucracy level & $1=\mathrm{L}$ or $\mathrm{H}=0$ & \multicolumn{3}{|c|}{ Less than $15 \%$ of all population is working at the go } \\
\hline
\end{tabular}

\section{OR= Old Regionalism}

NR= Hew Regionalism

FTA= Free Trade Area

$\mathrm{CU}=$ Custom Union

D= Democratic

ND= Non Democratic

$N E=$ Non Exist

$E=$ Exist

R= Right

L= Left

U= Unitary

F= Federalism

P= Presidential

Par= Parliamentary

Hote: * We are using in all QT measure, the average variation rate by decade

(e.g. Variation rate between 1960's and 1970's to anabzing decade of 1970's) 
TABLE 5

THE GLOBAL REGIONAL POLITICAL DEVELOPMENT SOURCES

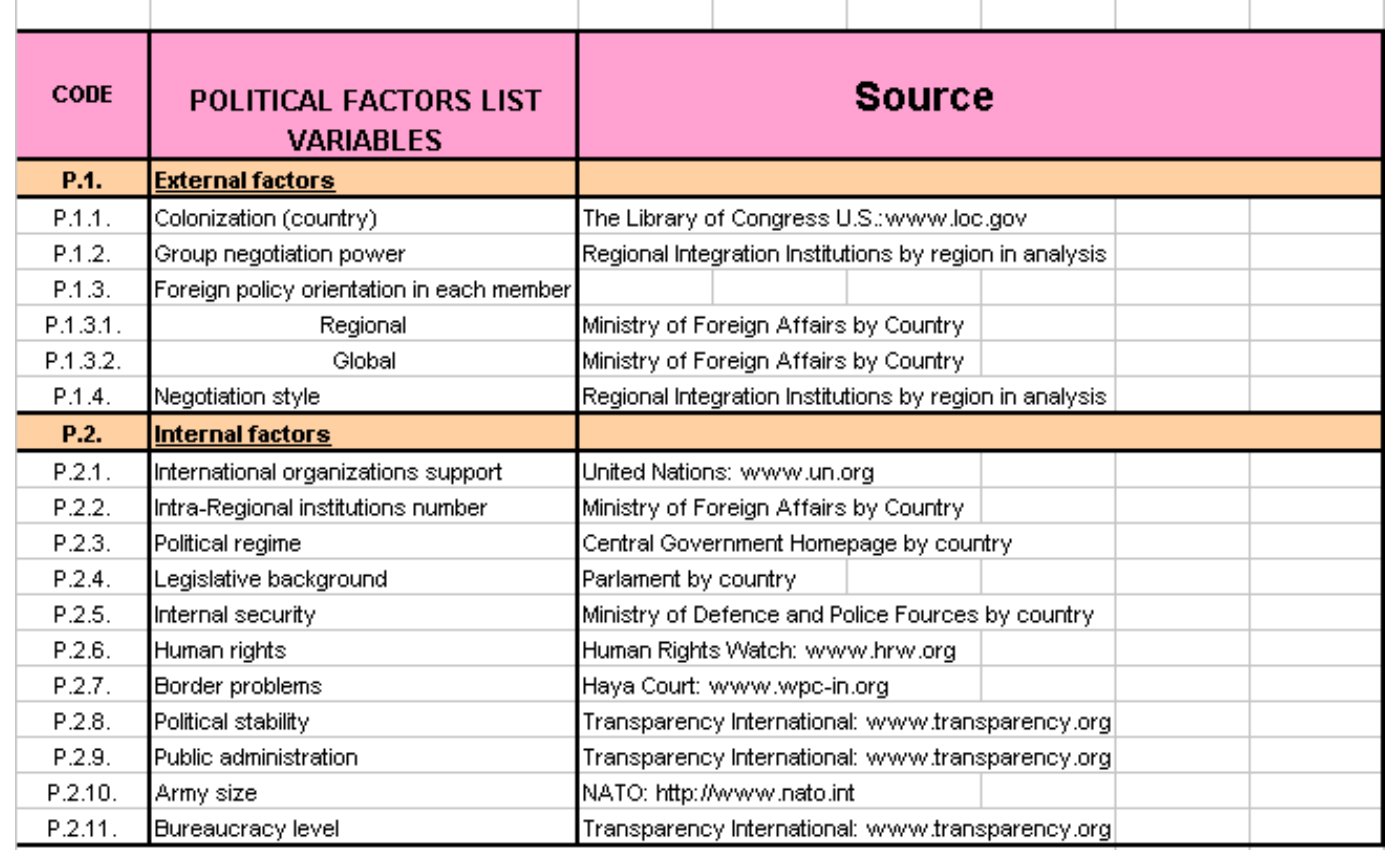

OR= Old Regionalism

HR= Hew Regionalism

FTA= Free Trade Area

CU= Custom Union

D= Democratic

ND= Hon Democratic

ME $=$ Mon Exist

$E=$ Exist

$\mathbf{R}=$ Right

L= Left

$\mathbf{U}=$ Unitary

F= Federalism

$\mathbf{P}=$ Presidential

Par= Parliamentary

Hote: */We are using in all QT measure, the average variation rate by decade

(e.g. Variation rate between 1960's and 1970's to anabying decade of 1970's) 
TABLE 6

MULTI-INPUT DATABASE TABLE: REGIONAL SOCIAL DEVELOPMENT OF TRADE BLOC "XYZ"

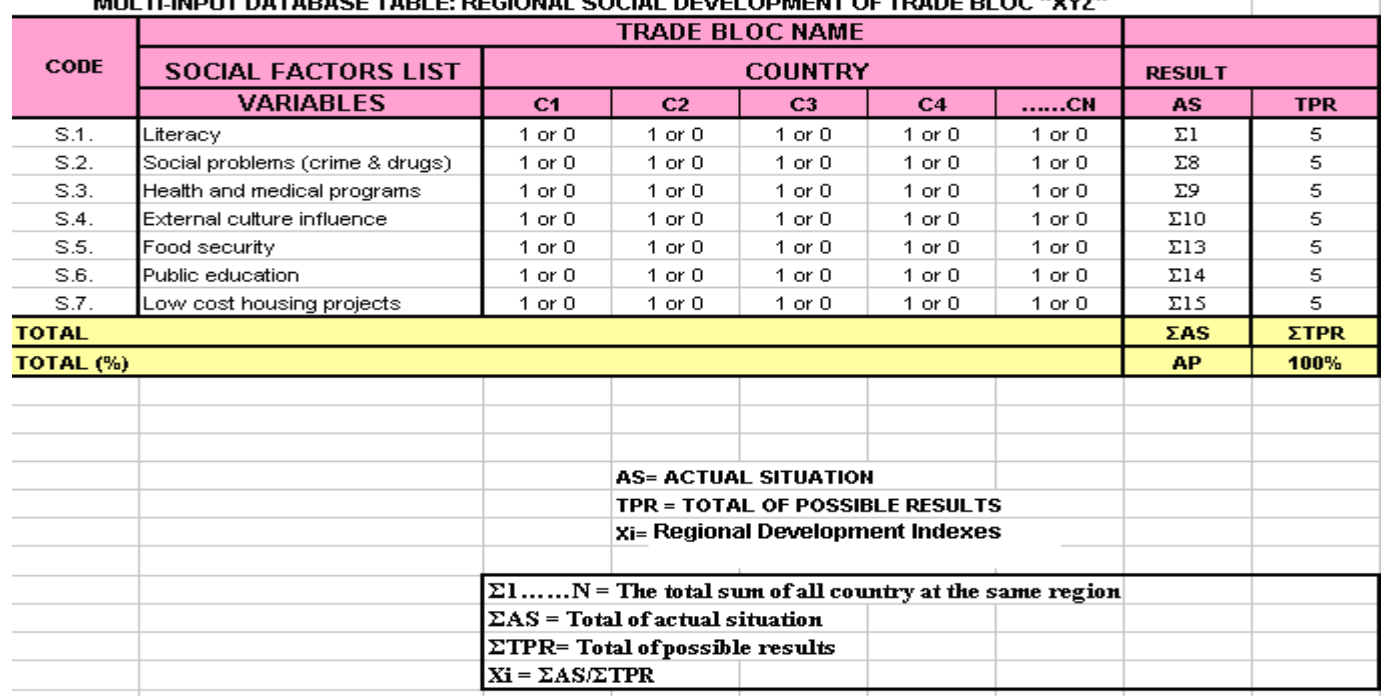

THE REGIONAL SOCIAL DEVELOPMENT PARAMETERS

\begin{tabular}{|c|c|c|c|c|}
\hline \multirow[t]{2}{*}{ CODE } & \multirow{2}{*}{$\begin{array}{c}\text { SOCIAL FACTORS LIST } \\
\text { VARIABLES }\end{array}$} & \multicolumn{3}{|c|}{ PARARIETERS } \\
\hline & & LIMIT & \multicolumn{2}{|l|}{ Source } \\
\hline S.1. & Literacy & $1=$ hlgh or $0=$ low & \multicolumn{2}{|l|}{$=70 \%$ of total population has education } \\
\hline S.2. & Social problems (crime \& drugs) & $1=$ low or $0=$ high & \multicolumn{2}{|c|}{ Out of the country list with higher crime and drugs } \\
\hline S.3. & Health and medical programs & $1=$ high or $0=$ low & \multicolumn{2}{|l|}{$=45 \%$ total of population has health care } \\
\hline S.4. & External culture influence & $1=$ exist or $0=N E$ & Cable T.V. Access & \\
\hline S.5. & Food security & $1=$ Exist or $0=$ NE & Programs in food security & \\
\hline S.7. & Low cost housing projects & $1=$ high or $0=$ low & Number of low cost housing projects & \\
\hline
\end{tabular}

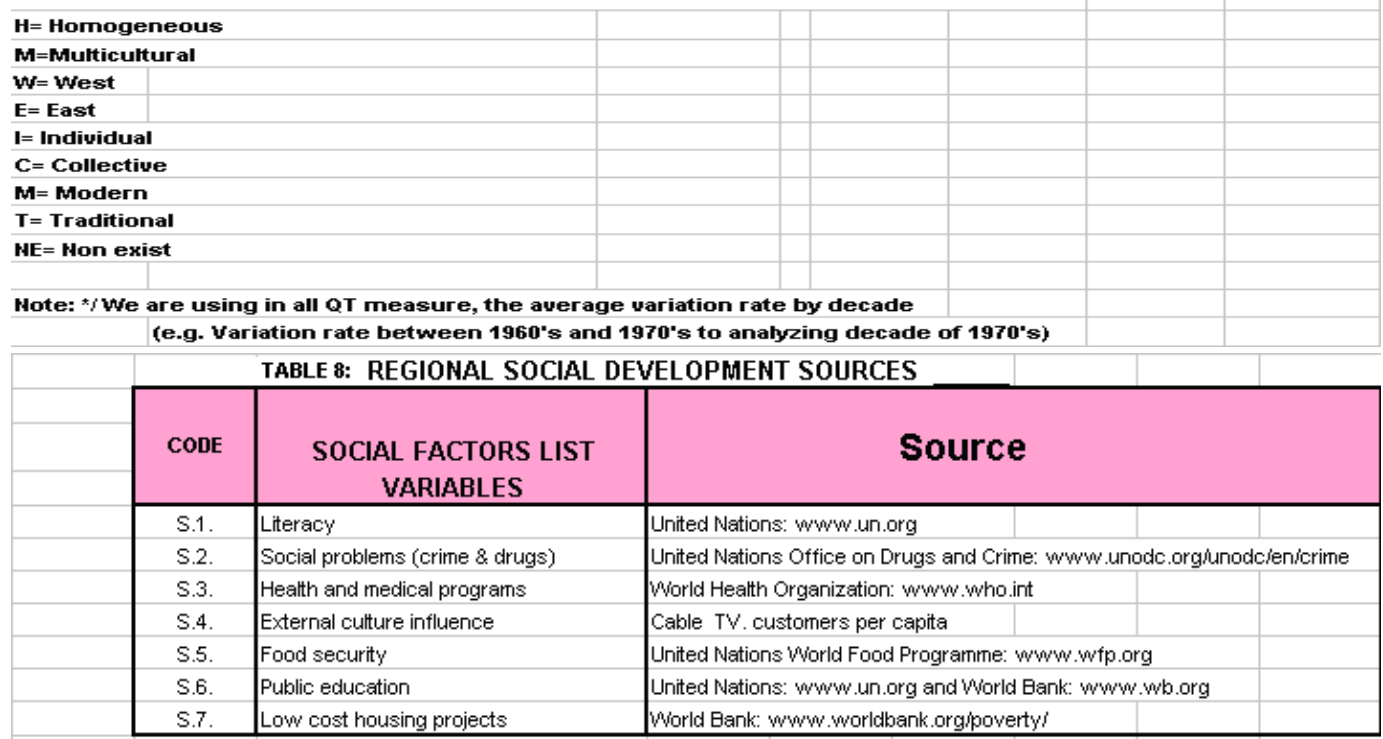


MULTI-IHPUT DATABASE TABLE: REGIOHAL ECOHOMIC DEVELOPMENT OF TRADE BLOC "XYZ"

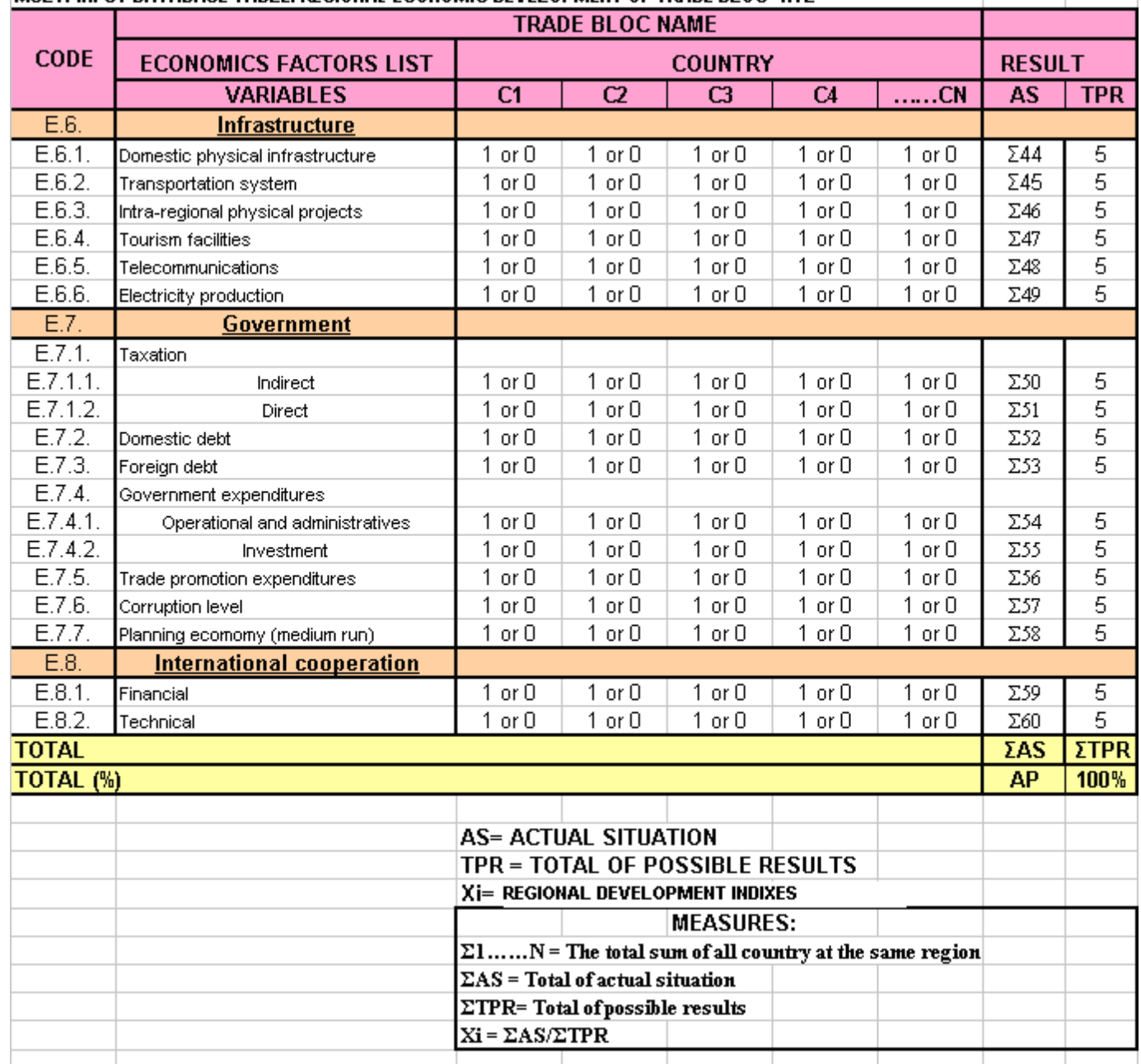


TABLE 10: REGIONAL ECONOMIC DEVELOPMENT PARAMETERS

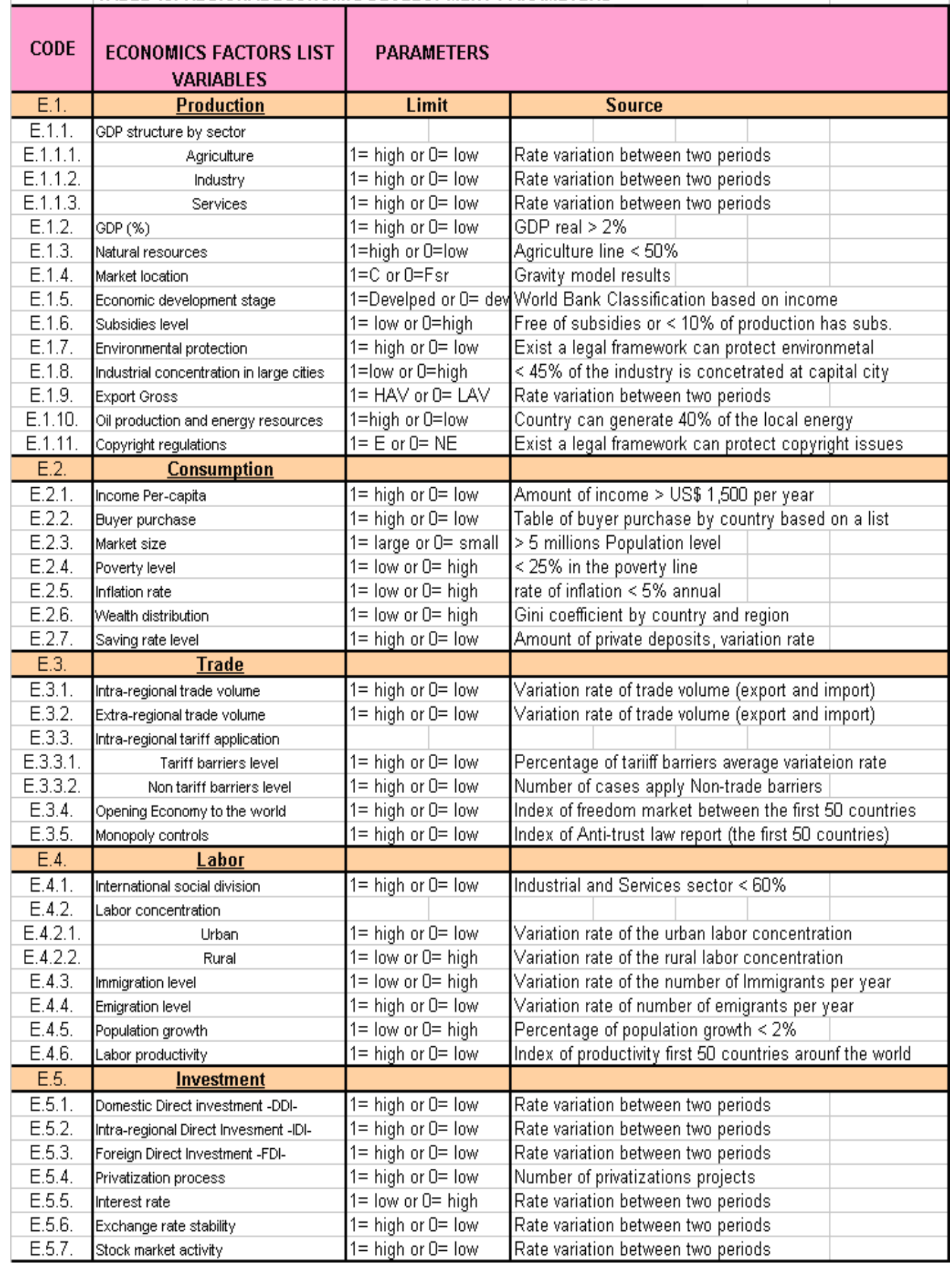


REGIONAL GLOBAL ECONOMIC DEVELOPMENT PARAMETERS

\begin{tabular}{|c|c|c|c|c|c|}
\hline \multirow[b]{2}{*}{ CODE } & \multicolumn{2}{|c|}{ REGIONAL GLOBAL ECONOMIC DEVELOPMENT PARAMETERS } & & & \\
\hline & $\begin{array}{c}\text { ECONOMICS FACTORS LIST } \\
\text { VARIABLES }\end{array}$ & \multicolumn{4}{|l|}{ PARAMETERS } \\
\hline E.6. & Infrastructure & & & & \\
\hline E.6.1. & Domestic physical infrastructure & $1=$ high or $0=$ low & \multicolumn{3}{|c|}{ Number of airports, ports, Km. highways and rail } \\
\hline E.6.2. & Transportation system & $1=$ cheap or $0=\exp$. & \multicolumn{3}{|c|}{ Prices level of basic transportation is using into the region } \\
\hline E.6.4. & Tourism facilities & $1=$ high or $0=$ low & \multicolumn{2}{|c|}{ Number of hotels and travel agencies } & \\
\hline E.6.5. & Telecommunications & $1=$ high or $0=$ low & \multicolumn{3}{|c|}{ Number of telecommunications companies } \\
\hline E.6.6. & Electricity production & $1=$ high or $0=$ low & \multicolumn{3}{|c|}{ Variation rate of electricity production per year } \\
\hline E.7. & \multicolumn{2}{|l|}{ Government } & & & \\
\hline E.7.1. & Taxation & & & & \\
\hline E.7.4. & Government expenditures & & & & \\
\hline E.7.4.1. & Operational and administratives & $1=$ high or $0=$ low & \multicolumn{2}{|c|}{ Rate variation between two periods } & \\
\hline E.7.4.2. & Investment & $1=$ high or $0=$ low & \multicolumn{2}{|c|}{ Rate variation between two periods } & \\
\hline E.7.5. & Trade\& Tourism promotion expenditures & $1=$ high or $0=$ low & \multicolumn{2}{|c|}{ Gov. expenditures variation rate } & \\
\hline E.7.6. & Corruption level & $1=$ high or $0=$ low & \multicolumn{3}{|c|}{ Outside from the first 50 countries with higher corruption } \\
\hline E.7.7. & Planning ecomomy (medium run) & $1=$ high or $0=$ low & \multicolumn{3}{|c|}{ Number of macro-prejects in the medium run } \\
\hline E.8. & International cooperation & 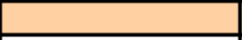 & & & \\
\hline E.8.1. & Financial & $1=$ high or $0=$ low & Rate variation between two & ods & \\
\hline E.8.2. & Technical & $1=$ high or $0=$ low & Number of trainig programs & & \\
\hline
\end{tabular}

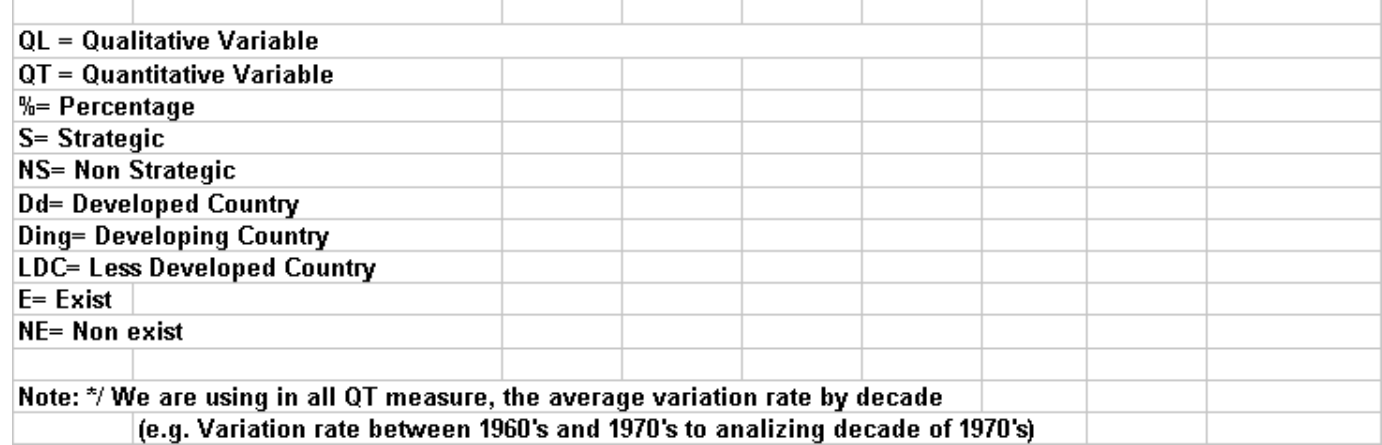


REGIOHAL ECOHOMIC DEVELOPMENT SOURCES

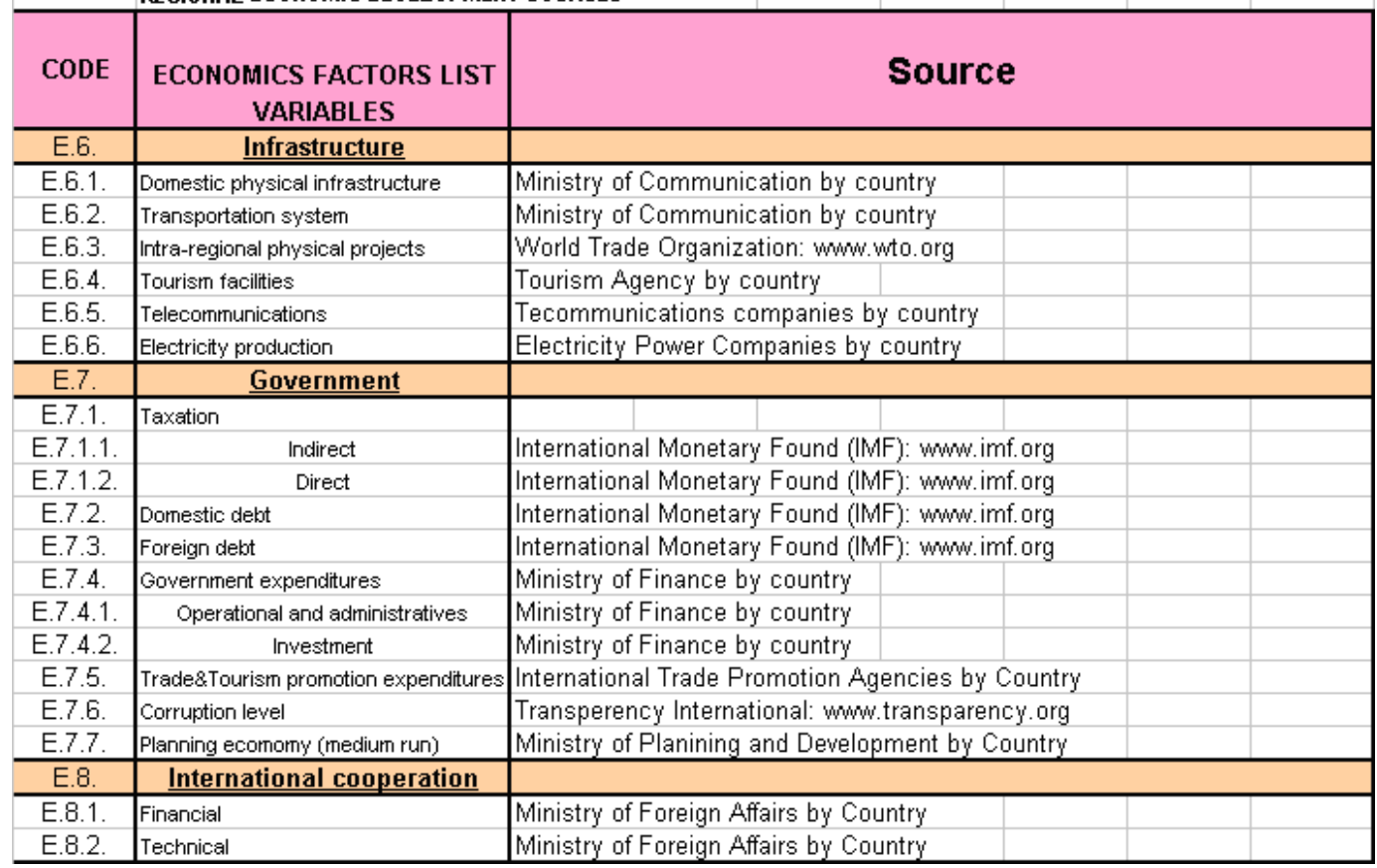

TABLE 12

MULTI-IHPUT DATABASE TABLE:REGIOHALTECHHOLOGICAL DEVELOPMENT OF TRADE BLOC "XYZ"

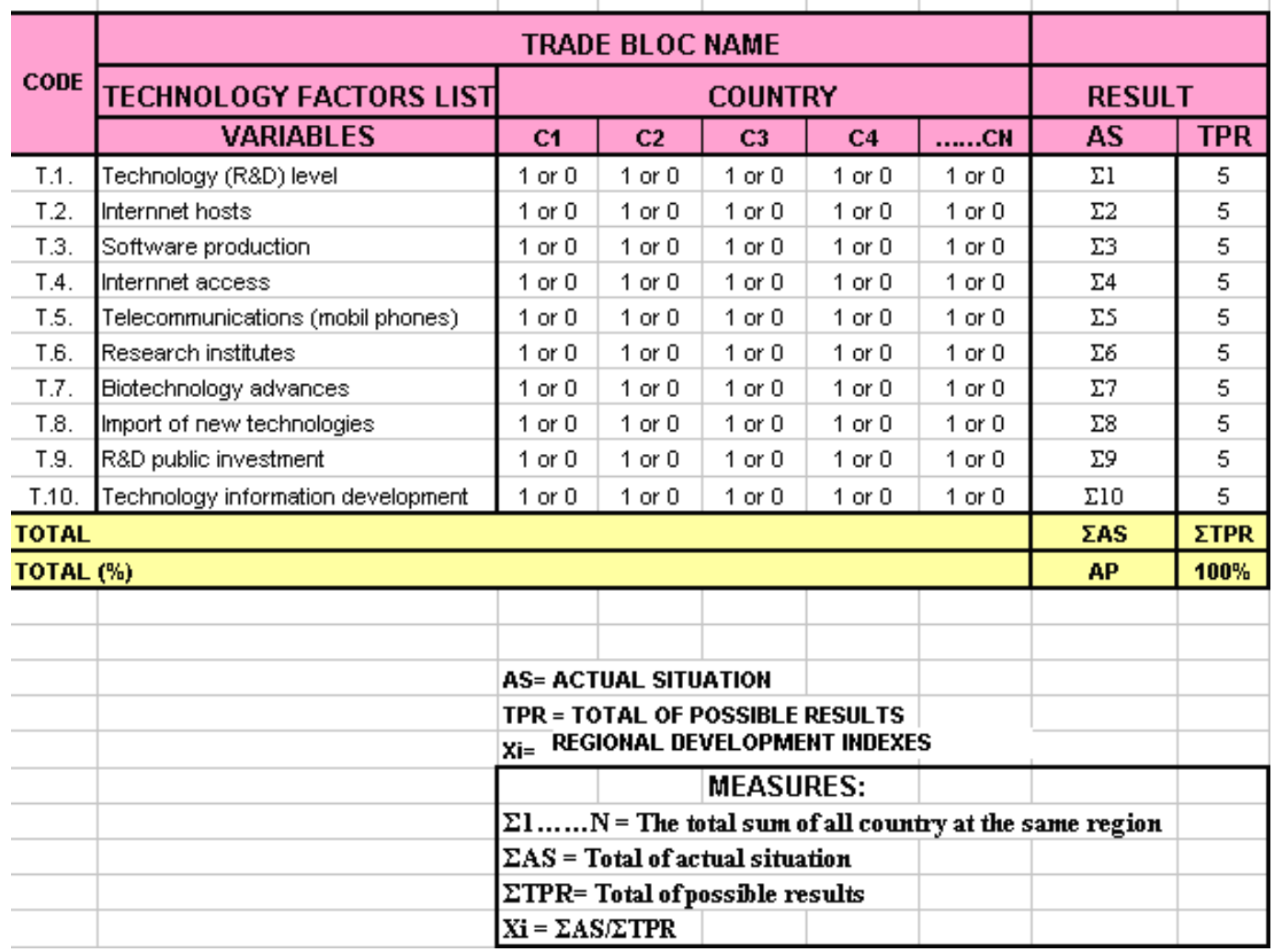


TABLE 13

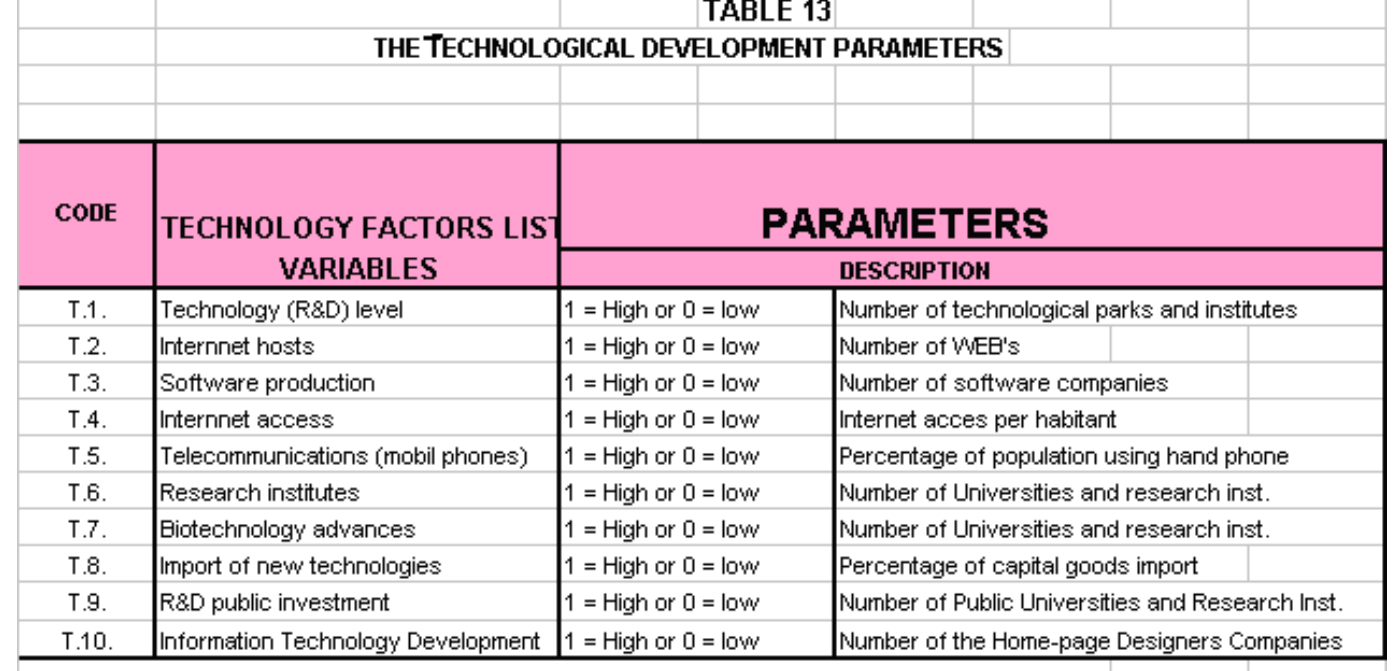

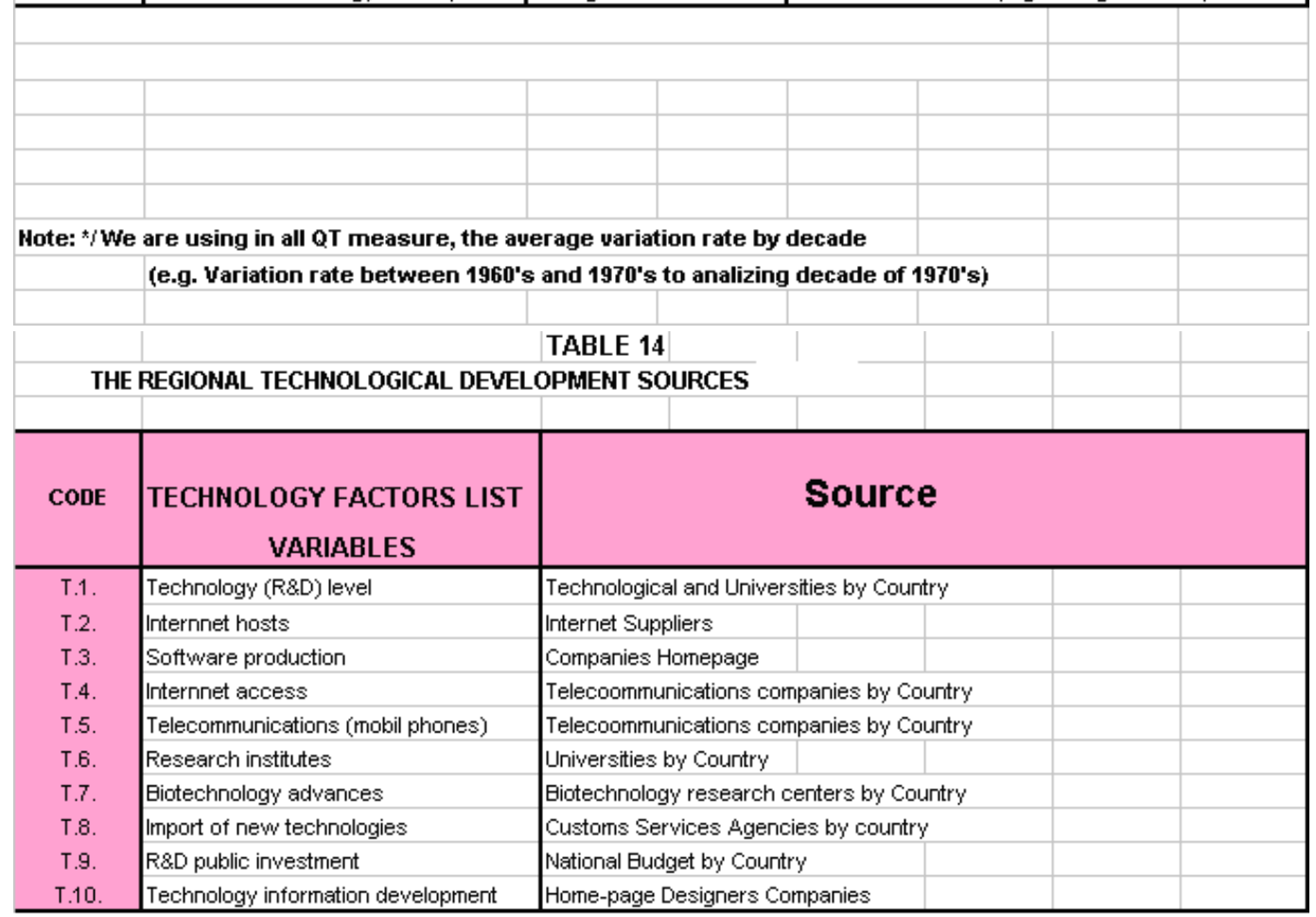

The parameters are divided into two categories. The categories are:

\section{(i) Quantitative Variables}

(i.a.) The measurement of Country Variation Rate (CVR) consists of two phases. The first phase is to measure the Variation Rate by Year (VRY) VRY is calculated based on two periods: present period data minus last period data divided by last period data. The data of each period can be in percentage or absolute values. In 
the second phase, is to define the average standard rate (ASR) that the researcher or policy maker is interested to apply.

$\mathrm{CVR}=\Sigma($ present period data - last period data) $/$ last period data

The ASR, it can then be compared against each CVR. The final result obtained presents two possible scenarios: first, if ASR $\leq$ CVR then this country obtains a value of 1 ; second, if $A S R \geq C V R$ then this country obtains a value of 0 .

\section{(ii) Qualitative Variables}

(ii.a.) Historical Data Focalization (HDF) can be classified by existence (i.e. an attempt is made to prove if $1=$ existing data or $0=$ non-existing data). This type of qualitative variables provides an alternative to measure non-quantitative variables that affect ranking in the development process of any country.

(ii.b.) Ranking List (RL) is originated from the best results of certain areas (social, economic, political and technological) in some countries. RL can be found in international organizations such as United Nations, World Bank, International Monetary Fund and etc. The size of the RL is determined by the researcher or policy maker interested to apply RL.

Ones the RL is established countries in the trade bloc can be compared. The RL can present two possible results: first, if the country is found in the RL, then this country receives a value of 1 ; second, if the country cannot be found in the RL, then this country receives a value of 0 .

The reason to use the binary system in each multi-input database table is that all variables have the same level of importance and weight in the study of the development process of any country. The binary system helps to maintain a balance among all variables in each multi-input database table. Another reason is that the binary system helps to create an alternative model of analysis countries with limited information, especially in the case of developing countries and less developed countries (LDC's). ${ }^{9}$

The number of variables used in the DGD-Model varies, depending on the objectives of the researchers or policy-makers and the orientation of the cases of research. In the case of this research paper, 128 head-variables with their respective parameters were selected: 15 head-variables for Domestic Political Development Index $\left(X_{1}\right)$ (see Table 3); 32 head-variables for Domestic Social Development Index $\left(X_{2}\right)$ (see Table 6); 65 head-variables for Domestic Economic Development Index $\left(X_{3}\right)$ (see Table 9) and 16 head-variables for Domestic Technological Development Index $\left(X_{4}\right)$ (see Table 12).

Once the number of variables is determined, the next step is to collect the statistical and historical data that constitute the variables. All variables in each multiinput database table may not have a direct relationship between them -- they may be dependent variables or exogenous variables. However, all the variables in each multi-

9 Mario A Ruiz Estrada, “The General Dimension of Regional Integration (GDRI)”, FEA 2004-7, Faculty of Economics and Administration Working Papers, University of Malaya, 2004, pp. $1-42$. 
input database table are meant to measure a single general variable, that is, each of the Domestic Development Indices $\left(X_{\mathrm{i}}\right)$.

Each of the four $X_{i}$ indices to be measured is viewed as a dependent variable (i.e. exogenous variable). However, there is no connection and interdependency among these four $X_{i}$ indices when they are joined in the graph. These four $X_{i}$ indices are used to draw a graph that represents the evolution and stages of the development process of any country from a General perspective.

\section{Steps to Obtain Domestic Development Indices $\left(X_{i}\right)$}

There are four Domestic Development Indices $\left(X_{i}\right)$ to be obtained. These four $X_{i}$ indexes are: Domestic Political Development Index $\left(X_{1}\right)$, Domestic Social Development Index $\left(X_{2}\right)$, Domestic Economic Development Index $\left(X_{3}\right)$ and Domestic Technological Development Index $\left(X_{4}\right)$. The first step is to define all variables and parameters. Once all the variables and parameters are defined, all the data based on the variables and parameters is listed in each multi-input database table.

The next step is to add up the values of all variables in the column of the Actual Situation (AS) in each multi-input database table. The Total Possible Results (TPR) obtained are then located in the TPR column next to AS column. With TPR in place, the next step is to compute each Domestic Development Indices (Xi). The computation is done by applying the expression (1) to the values in the multi-input database tables.

$$
\mathrm{Xi}=\underset{\mathrm{i}=1}{\stackrel{4}{\mathrm{i}}=\Sigma \mathrm{AS}_{(\mathrm{i})} \times 100 / \Sigma \mathrm{TPR}_{(\mathrm{i})}}
$$

Following the above four steps, the fifth step is the plotting of two graphs: (a) the Domestic Development Indices $\left(X_{i}\right)$ (see Graph 1), (b) the regional Political, social, Economic and Technological Diagnostic (see Graph 2). The latter graph serves as a means for studying the balance between achievements and difficulties that any country may experience in its development process.

\section{Introduction to Analysis of DGD-Area and DGD-Stage Based on General Development Indices (Xi)}

Each Domestic Development Indices $\left(X_{i}\right)$ plays an important role in the measurement of the Domestic General Development Area (DGD-Area) and the Domestic General Development Stage (DGD-Stage). These two indices can be affected by any change in the $X_{i}$ indices in the short and long run. The $X_{i}$ indices may reflect one of two different scenarios. First, if some or all-Domestic General Development Indices are political $\left(X_{1}\right)$, social $\left(X_{2}\right)$, economic $\left(X_{3}\right)$ and technological $\left(X_{4}\right)$ increase, then DGD-Area and DGD-Stage may increase. The second scenario is, if some or all-Domestic Development Indices $\left(X_{i}\right)$ by area of development (political, social, economic and technological) decrease, then the DGD-Area and DGD-Stage may decrease. 
GRAPH 1

The Domestic Development Indices $\left(\mathrm{X}_{\mathrm{i}}\right)$ DIAGRAM
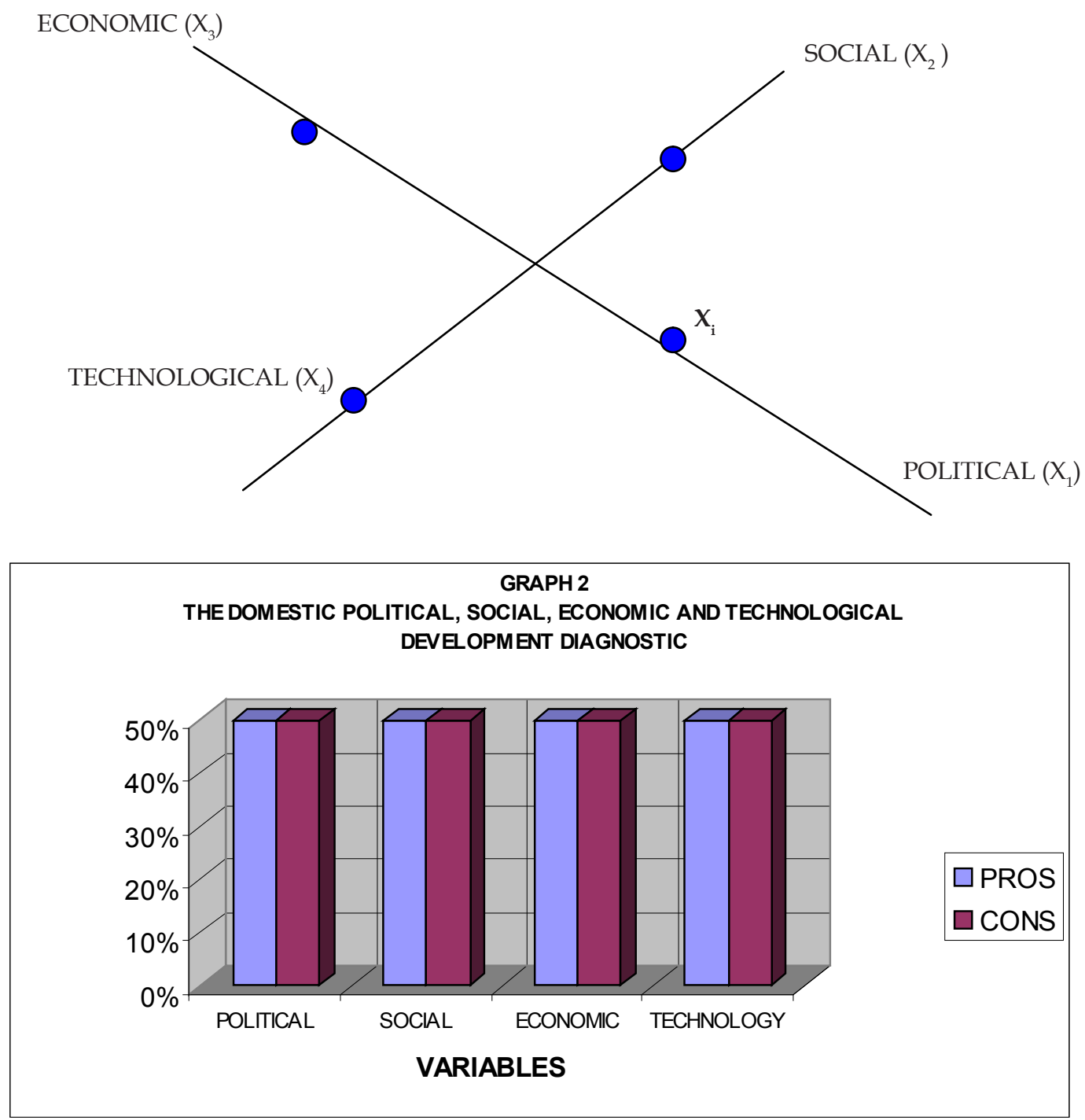

Phase III: Measurement of the Domestic General Development Area of Coverage (DGD-Area)

The third phase of the implementation of the DGD-Area presents a general definition about the Domestic General Development Area (DGD-Area). The DGD-Area is an indicator to compare different historical periods of the development process of any country. It is based on the Domestic Development Indices $\left(X_{i}\right)$ of a country. Therefore, the DGD-Stage is a means of analyzing the development evolution of any country from a General perspective. 


\section{Steps to Obtain the DGD-Area}

The first step is to plot each $\left(X_{i}\right)$ index: Domestic Political Development Index $\left(X_{1}\right)$, Domestic Social Development Index $\left(X_{2}\right)$, Domestic Economic Development Index $\left(X_{3}\right)$ and Domestic Technological Development Index $\left(X_{4}\right)$ on the Cartesian plane (see Graph 3 and Graph 5). It should be noted that each DGD-Stage value (single percentage) is an approximation of the past and present situations that any country may encounter in its domestic General development evolution. The DGD-Area is the summation of all the four Domestic Development Indices $\left(X_{i}\right)$.

The second step is to plot the DGD-Indices graph based on the total value of the four Domestic Development Indices $\left(X_{\mathrm{i}}\right)$. This is followed by calculation of the Domestic General Development Area (DGD-Area) based on expression (2). It should be noted that the values of the $X_{i}$ indices are independent of one another. The DGD-Area graph consists of four different areas, where each area has a limit equivalent to 0.25 . The total value of these four areas is equal to 1 as observed in the expression (2.5.)

Each axis of Graph 3 and Graph 4 is either the base or the height of the graph (represented by $\mathrm{B}$ and $\mathrm{H}$ respectively in the graph). The DGD-Area 1 uses the result of the General development index in the axis $\mathrm{X}_{1}$ which is equal to $\mathrm{B}_{1}$, and the General development index in the axis $X_{2}$ which is equal to $H_{1}$, follow by application of (2.1.) The same steps and expression are used for DGD-Area of Coverage 1, DGD-Area of Coverage 2, DGD-Area of Coverage 3 and DGD-Area of Coverage 4 (see graph 4). The total DGD-Stage for this period is the sum of all the DGD's. This is depicted in expression (2.5.)

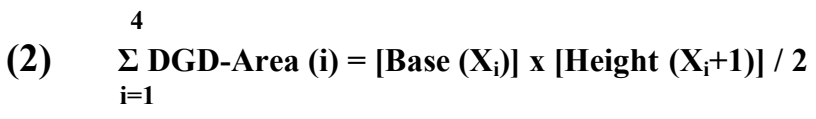

2.1. ) $\left[\mathrm{B}_{1}=\mathrm{H}_{4}\right]$ : DGD-Area of Coverage $1=\left[\mathrm{X}_{1}\left(\mathrm{~B}_{1}\right), \mathrm{X}_{2}\left(\mathrm{H}_{1}\right)\right] / 2$

2.2. ) $\quad\left[B_{2}=H_{1}\right]$ : DGD-Area of Coverage $2=\left[X_{2}\left(B_{2}\right), X_{3}\left(H_{2}\right)\right] / 2$

2.3. ) $\quad\left[B_{3}=H_{2}\right]$ : DGD-Area of Coverage $3=\left[X_{3}\left(B_{3}\right), X_{4}\left(H_{3}\right)\right] / 2$

2.4. ) $\quad\left[B_{4}=H_{3}\right]$ : DGD-Area of Coverage $4=\left[X_{4}\left(B_{4}\right), X_{1}\left(H_{4}\right)\right] / 2$

2.5. ) DGD = DGD-Area of Coverage $1+$ DGD-Area of Coverage $2+$ DGD-Area of Coverage 3 + DGD-Area of Coverage 4

$B=$ Base $\quad H=$ Height $\quad X_{i}=$ initial actual panorama $\quad X_{i}+1=$ next actual panorama Analysis of DGD-Area

The analysis of the DGD-Area is based on the comparison of two periods or regions. In the case of this research paper, two periods (i.e. first period and second period) are compared. The total DGD-Area may present three possible scenarios, namely (a) expansion (DGD-Area' first period < DGD-Area" second period), (b) stagnation (DGD- 
Area' first period = DGD-Area" second period) and (c) contraction (DGD-Area' first period > DGD-Area" second period).

In terms of time-span, the DGD-Area can be measured and compared on a yearly basis, five-yearly basis, and by decades. For this research, the time-span is one year (2004), which can later be compared. In terms of space, the DGD-Area can be measured and compared in development process of sixteen countries. At any historical moment, the development process in any region is based on the comparison of the size of the Domestic General Development (DGD-Area).

Graph 3

The Domestic General Development Area (DGD-Area)

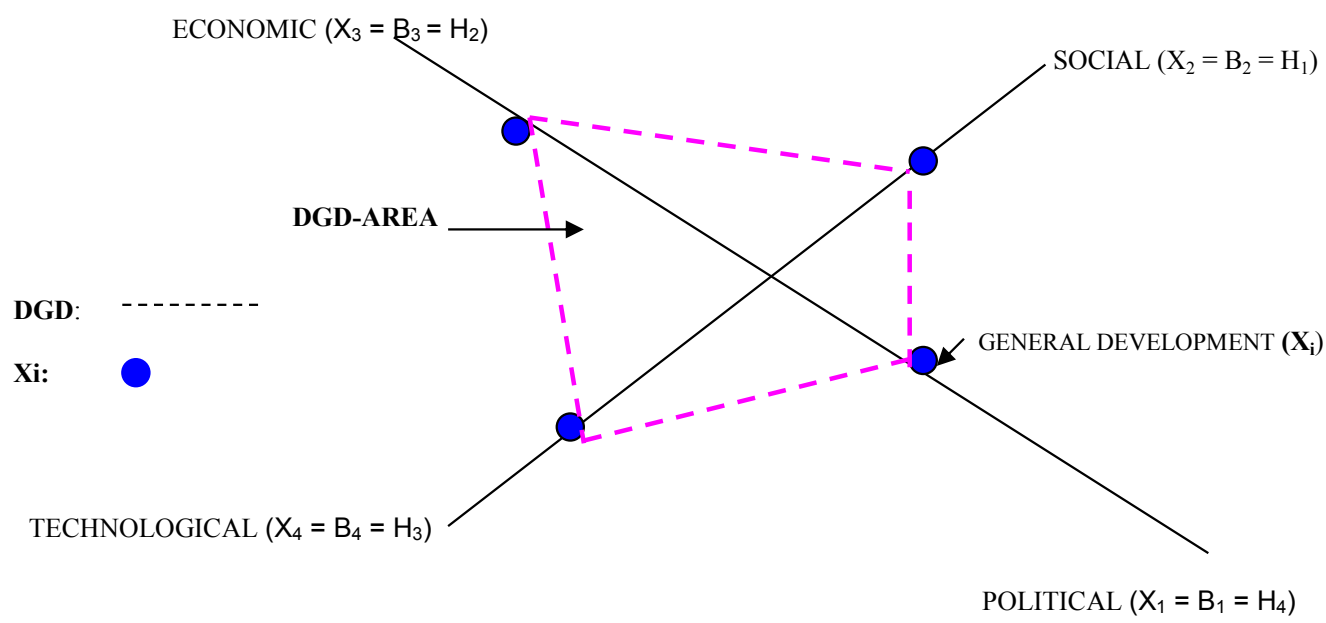

Graph 4

Areas of Rotation Applied To DGD-Area

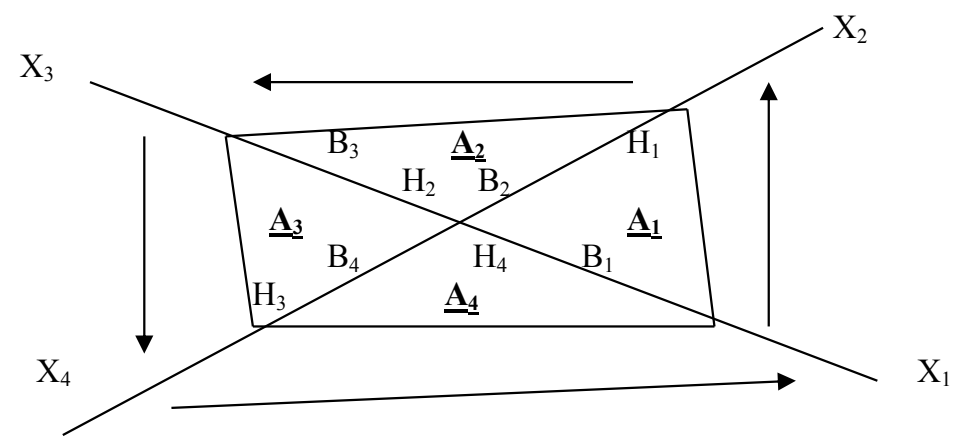




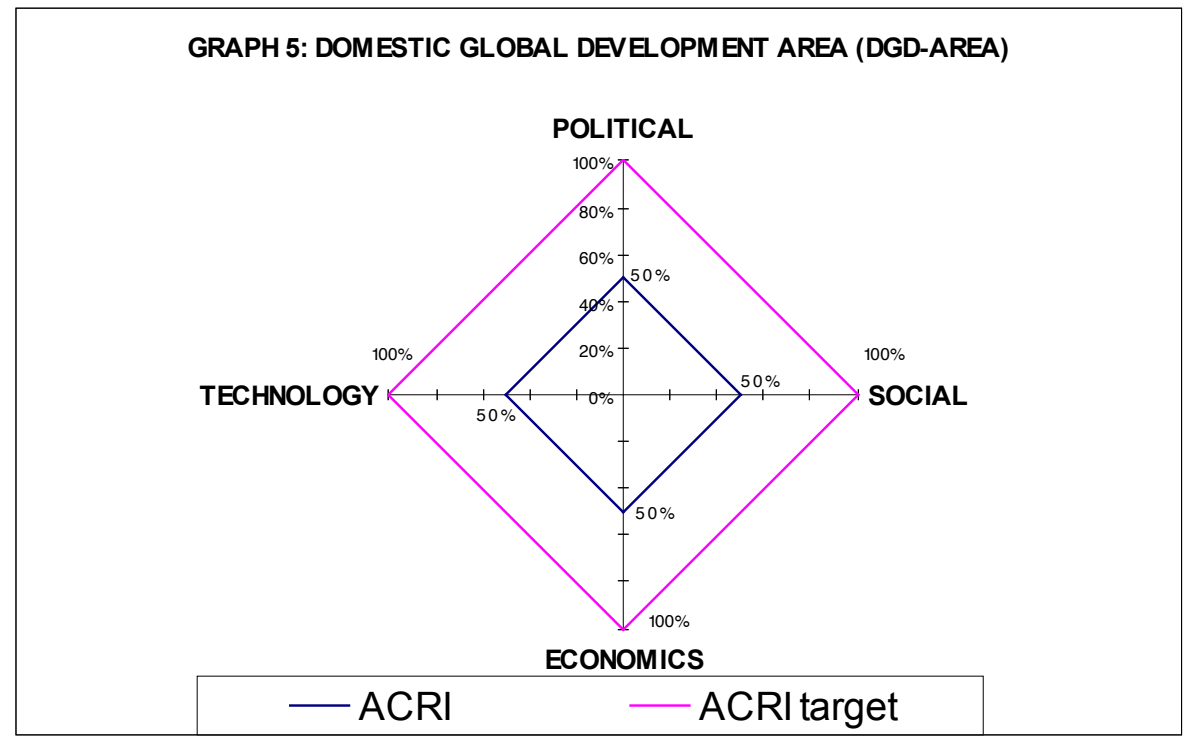

Phase IV: Measurement of the Domestic General Development Stage (DGD-Stage)

The last phase in the implementation of the DGD-Stage is the measurement of the Domestic General Development Stage (DGD-Stage). The DGD-Stage measures the degree or stage of the development stage that any country achieves in its different stages of evolution. The DGD-Stage is considered a dependent variable. In the measurement of the DGD-Stage, four Domestic Development Indices $\left(X_{\mathrm{i}}\right)$ are used: Domestic Political Development Index $\left(X_{1}\right)$, Domestic Social Development Index $\left(X_{2}\right)$, Domestic Economic Development Index $\left(X_{3}\right)$ and Domestic Technological Development Index $\left(X_{4}\right)$. A constant coefficient - Domestic Development Approach Incline (DDAI) -- is also used concurrently. The DDAI is represented by a, b, c, and d in expression (3) and is applied to each General development indices $\left(X_{i}\right)$. Each DDAI $(a, b, c$, or $d)$ has a limit that is equal to 1. [Refer to expression (3)]. The sum of the DDAI's cannot be more than 1.

The application of the DDAI is twofold. The first application is the DDAI Homogeneous Interest. In this application, each DDAI has the same level of importance in the analysis [Refer to expression (3.1.)]. The second application is the DDAI Incline. There are four possibilities in this application: political approach incline (3.2.), social approach incline (3.3.), economic approach incline (3.4.) and technological approach incline (3.5.)

\section{Analysis of DGD-Stage}

After the type of DDAI to be applied is determined, the Domestic General Development Stage (DGD-Stage) is measured according to expression (3). The DGD-Model may reveal one of three different scenarios, namely (a) under-developed stage $(0 \leq$ DGDStage $\leq 0.33)$, (b) developing stage $(0.34 \leq$ DGD-Stage $\leq 0.66)$ and (c) developed stage $(0.67 \leq$ DGD-Stage $\leq 1)$. The analysis of the DGD-Stage can provide a general idea or approximation of the stage of regional integration achieved in any region through time and space. 
The following is a suggested combination of the application of the DDAI in the measurement of the DGD-Stage:

$$
\mathrm{Y}=\mathrm{DGD}=\mathrm{a} \mathrm{X}_{1}+\mathrm{b} \mathrm{X}_{2}+\mathrm{c} \mathrm{X}_{3}+\mathrm{d} \mathrm{X}_{4} \leq 1
$$

(3.1.) $\mathrm{a}=0.25, \mathrm{~b}=0.25, \mathrm{c}=0.25, \mathrm{~d}=0.25=1=>$ DDAI homogeneous interest

(3.2.) $\mathrm{a}=0.40, \mathrm{~b}=0.20, \mathrm{c}=0.20, \mathrm{~d}=0.20=1=>$ DDAI political approach incline

(3.3.) $\mathrm{a}=0.20, \mathrm{~b}=0.40, \mathrm{c}=0.20, \mathrm{~d}=0.20=1 \Rightarrow$ DDAI social approach incline

(3.4.) $\mathrm{a}=0.20, \mathrm{~b}=0.20, \mathrm{c}=0.40, \mathrm{~d}=0.20=1=>$ DDAI economic approach incline

(3.5.) $\mathrm{a}=0.20, \mathrm{~b}=0.20, \mathrm{c}=0.20, \mathrm{~d}=0.40=1=>$ DDAI technological approach incline

It must be highlighted that the above combination represents only several of many possibilities or permutations. This should draw attention to the flexibility of the DGD-Stage in adapting to any situation or chosen policy mode. The DGD-Stage presents an approximation of the General development from political, social, economic and technological perspectives concurrently based on a new concept of graphic representation (see Graph 6).

This new concept of graphic representation consists of five axes, each of which has a positive value. (In the case of this research, the value in each axis is represented by a percentage). Once the axes of the graph are in place, the next step is to plot the four $\mathrm{X}_{i}$ indices (politics, social, economic, and technology $X_{i}$ indices) in four of the axes respectively. These $\mathrm{Xi}$ indices are independent variables. The total value of the four axes is equal to 1. (see Graph 6).

The fifth axis, which is represented by $\mathbf{Y}$ and positioned in the center of the graph (among the other four axes) represents the dependent variable DGD-Stage. This fifth axis is the convergent point of all the other four axes or more precisely, the four indices -political, social, economic, and technological- of Domestic Development Indices $\left(\mathrm{X}_{\mathrm{i}}\right)$.

The DGD-Stage (Y) is depicted as follows in expression (4):

$$
Y=F\left(X_{1}, X_{2}, X_{3}, X_{4}\right) \leq 1
$$

\section{The Domestic General Development of China}

All the above-mentioned analytical methodologies persist in measuring changes of welfare based on the evaluation of basic variables in the study of development process of any country. This research paper, on the other hand, asserts that the study of the development should not merely focus on the traditional scheme of indicators; instead it should take into consideration a new alternative analytical toolbox based on a new serial of indicators and graphs to doing a deep analysis of countries from a General perspective. On this account, this paper further maintains that the study of development process of China requires simultaneous inclusion of social, economic, political and technological dimensions of research.

The central objective of our paper is to contribute to the literature on China development study by examining China from a more global perspective that encompasses not only the economic dimension but other relevant dimensions as well. 
To do so, we use the Global Dimension of Regional Integration Model (henceforth DGD Model) recently developed by Ruiz (2004). The defining characteristic of the model, which we discuss in the next section, is that it looks at regional development simultaneously from political, social, economic and technological perspectives. We apply the model to a comparative analysis of the development levels of China in the 1980s, 1990s and 2000-2015.

Graph 6

The Graph of the Domestic General Development Stage (Dgd-Stage)

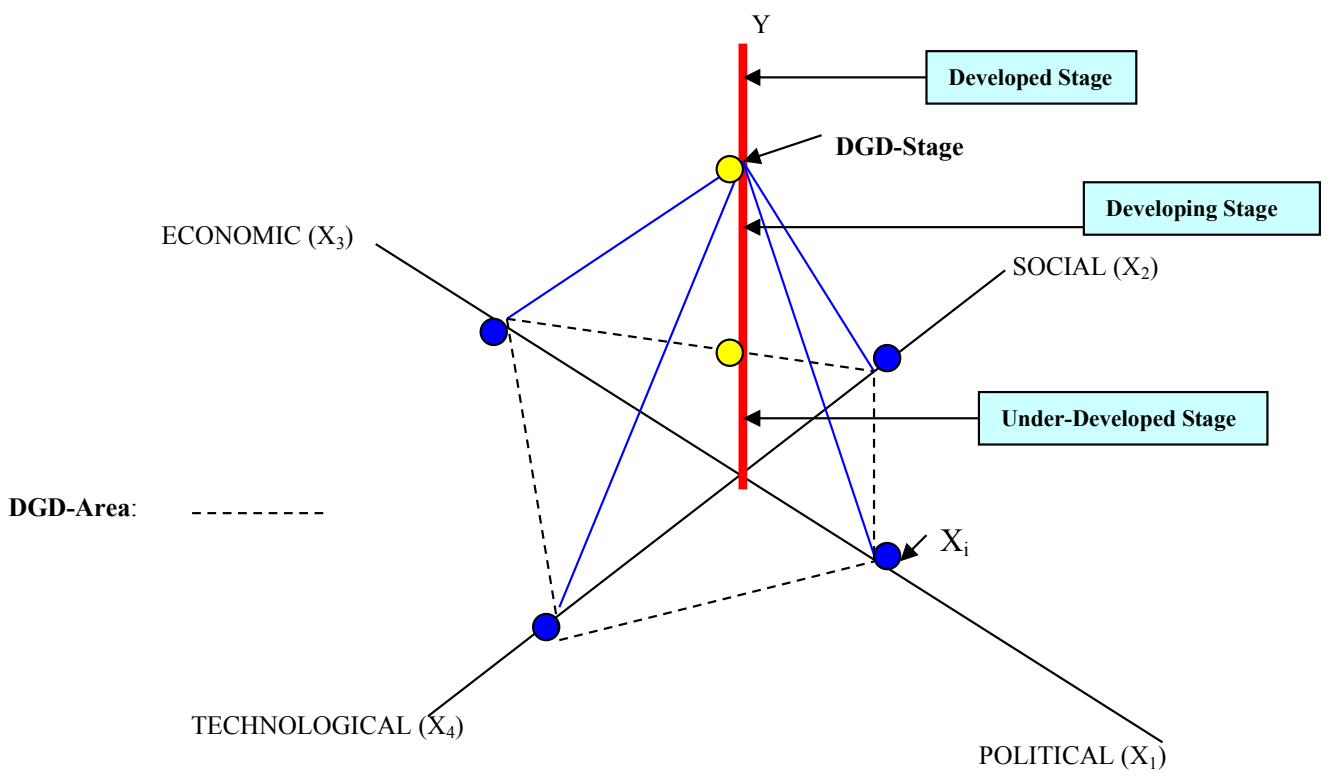

DGD-Stage: Domestic General Development Stage

DGD-Area: Domestic General Development Area of Coverage

$\mathrm{X}_{\mathrm{i}}$ : Domestic General Development Indices

In this research has been divided China study between West China (inland) and East China (coastal). The two sides of China share a common people, history and culture, and the political division. Nevertheless, the division is used to analyze the gap of development between the two country sides. Continuous rapid growth has transformed of China into more fast growth region around the world into an economic powerhouse that exports manufactured goods all over the world. China is now one of the world's 10 biggest economies and home to a growing number of local and transnational companies. Furthermore, China is no longer merely a technological follower but has become a manufacturer leader in some areas, most notably in electronics and basic goods manufactured. In contrast, past decades between 1940's and 1960's originated by the central planning (government intervention on the economy) have reduced China to one of the poorest countries in the world but in the period between 1980's and 1990's China (Collapse of U.R.S.S. and deep ideological reforms at U.R.S.S. based on Perestrika) start to open spaces to develop more fast the Chinese economy. 
Let us now discuss each of the four basic phases, beginning with the design of the multi-input database table. The multi-input database table and shows global regional political development. Global refers to the multidimensional nature of political development and is represented by a wide range of political variables. Regional refers to the specific region of interest to the research. Therefore, in our case, global regional political development refers to the political development of the China as measured by the 15 political variables in Table 3, 4 and 5 . There is no reason why the number of variables in a multi-input database table should be constant and it can vary according to the objectives of the research and data availability. We can similarly construct multi-input database tables for global regional economic, social and technological development.

The second phase of the DGD Model is to measure the Global Development Indexes (Xi) using the variables in the four multi-input database tables described above. The four Global Development Indexes are the Global Political Development Index $\left(X_{1}\right)$, Global Social Development Index $\left(X_{2}\right)$, Global Economic Development Index $\left(X_{3}\right)$ and Global Technological Development Index $\left(X_{4}\right)$. The data we input for each country in the region - in our case, East China (coastal) and West China (inland) are the two large regions of China in our study - are based on statistical and historical data. Furthermore, all our data are binary - i.e. either 1 or 0 - and determined by either quantitative or qualitative criteria. A big reason for using binary data is that we attach the same level of importance to all the variables in our multi-input database tables. Another reason for using binary data is that it allows us to analyze countries with limited data, such as West China (inland).

We can similarly input binary data for all the variables in the multi-input database tables for social, economic and technological development of East and West China (inland) from 1980 to 2012. The variables that are used to measure social development are shown in Table 3, 6, 9 and 12 below. We find the global social development of East China (coastal) and West China (inland) in the 1980s to be $60 \%$ and $30 \%$, respectively. We find the global economic development of East China (coastal) and West China (inland) in the 1990s to be $45 \%$ and 15\%, respectively. We find the global technological development of East China (coastal) and West China (inland) in the 1980s to be 65\% and $35 \%$, respectively.

The third phase of the DGD Model is to use the four Global Development Indices $\left(X_{i}\right)$ we found in the model's second phase - i.e. political, social, economic and technological - to estimate the Global Overall Development Index (X), which sums up the information contained in the four indices. Intuitively, the Global Overall Development Index $(X)$ measures a country's overall level of development from a multidimensional or global perspective encompassing political, social, economic and technological development. Furthermore, as we saw earlier, we measured political, social, economic and technological development themselves from a multidimensional or global perspective, using a wide range of variables relevant to the development of each sphere.

The first step in estimating the Global Overall Development Index $(X)$ is to plot the values of the four Global Development Indices $\left(X_{i}\right)$, as shown in Figure 1 below. This graph will help to illustrate how we compute X. Graph 1 consists of four different triangular areas - each bounded by the values of two of the four global development indices - for West China (inland), East China (coastal) and the Chinas. Let us define the 
triangular area between the political and social axes as $\mathrm{A}_{1}$, social and economic axes as $\mathrm{A}_{2^{\prime}}$ economic and technological axes as $\mathrm{A}_{3^{\prime}}$ and technological and political axes as $\mathrm{A}_{4}$. Each area has a maximum value of 0.25 and the total value of the four areas is 1 .

We compute the overall global development index $(X)$ as the sum of the four areas - A1, A2, A3 and A4. In computing A1, it is useful to think of the value of the Global Political Development Index $\left(X_{1}\right)$ as the base and the value of the Global Social Development Index $\left(X_{2}\right)$ as the height. We compute A1 by first multiplying $X_{1}$ and $X_{2^{\prime}}$ and then dividing their product by four. Similarly, we can compute $A_{2}, A_{3}$ and $A_{4}$ by doing the same with the pairs $\left(X_{2^{\prime}}, X_{3}\right),\left(X_{3^{3}}, X_{4}\right)$ and $\left(X_{4^{\prime}}, X_{1}\right)$, respectively. For example, for East China (coastal), $A 1$ is $7 \%$ since $X_{1}$ is $50 \%$ and $X_{2}$ is $8 \%$. Likewise, we compute $A_{2}$, $\mathrm{A}_{3}$ and $\mathrm{A}_{4}$ for West China (inland) to be $6 \%, 6 \%$ and $8 \%$. Therefore, East China (coastal) overall global development index $(X)$ is $30 \%$. We can similarly compute $X$ for West China (inland) as 5\%. Therefore, in the 1980s, West China (inland)'s overall development level was about eight times higher than that of East China (coastal).

The fourth and final phase of the DGD Model is to use the four Global Development Indices (Xi) and coefficients to measure the Global Development Stage (Y) of West China (inland) and East China (coastal). The coefficient indicates the relative importance of the political, social, economic and technological dimensions, and sum up to one. For example, if we attach equal importance to the four dimensions, the coefficient for each dimension is 0.25 . To obtain the Global Development Stage (Y), we first multiply the Global Development Index $\left(X_{i}\right)$ with the corresponding coefficient - for example, the Global Political Development Index $\left(X_{1}\right)$ and the political coefficient - and then sum up the four products. Assuming that each of the four coefficients is 0.25 , so that the four dimensions are equally important, we can compute the Global Development Stage (Y) for East China (coastal) and West China (inland) as 50\% and 23\%, respectively, in the 1990s. The large gap in Y between West China (inland) and East China (coastal) indicates a large gap between the two countries in terms of overall development. Figure 2 below provides a graphical representation of Global Development Stage (Y). The height corresponds to $\mathrm{Y}$ and the quadrangular area inside the dotted lines corresponds to the Overall Global Development Index (X).

The Global Development Stage $(\mathrm{Y})$ is broadly similar to the Global Overall Development Index $(X)$ since both reflect the overall development level of a country or a region. We define a value of $Y$ between $0 \%$ and $33 \%$ as the underdeveloped stage, $37 \%$ and $70 \%$ as the developing stage, and $70 \%$ and $100 \%$ as the developed stage. Therefore, in the 1990s, East China (coastal) was in the developing stage whereas West China (inland) was in the underdeveloped stage. We should note that $Y$ is more flexible than $X$ in the sense that it allows us to attach any combination of relative weights to the political, social, economic and technological dimensions. For example, if we attach more importance to the political dimension than the other dimensions, the political coefficient may be 0.40 while the social, economic and technological coefficients may each be 0.20 . More generally, we can flexibly vary the relative sizes of the four coefficients to suit our needs.

We now report the main results of our DGD Model analysis of the two China during the 1980s and the 1990s. East China (coastal)'s Global Political Development Index $\left(X_{1}\right)$ increased from $50 \%$ in the 1980 s to $70 \%$ in the 1990 s and $80 \%$ in the $2000-2012$, which indicates that East China (coastal) has become progressively more politically developed over time. The social development of East China (coastal) has moved significantly 
forward in the 1990s and 2000-2012, in contrast to West China (inland), which has failed to make any progress in this area. East China (coastal) Global Social Development Index $\left(X_{2}\right)$ rose from $60 \%$ in the 1980 s to $90 \%$ in the 1990 s and $100 \%$ in the $2000-2012$. To a large extent, this reflects East China (coastal)'s rapid economic development since basic social services such as healthcare and education tend to improve with a country's living standards. In stark contrast, the same index declined from 30\% in the 1980s and 1990 s to $15 \%$ in the $2000-2012$ for West China (inland), and this decline parallels the country's steep economic decline.

The East China (coastal) economy has achieved rapid growth and development, in sharp contrast to the West China (inland) economy, which has deteriorated sharply over time. East China (coastal)'s Global Economic Development Index $\left(\mathrm{X}_{3}\right)$ has more than doubled, from $45 \%$ in the 1980 s to $75 \%$ in the 1990 s and $84 \%$ in the $2000-2012$. This is consistent with the country's radical transformation from a poor developing country to a highly successful newly industrialized economy (NIE) that has become a model of economic development for the Third World. On the other hand, for West China (inland), the same index has plummeted from $15 \%$ in the 1980 s to $5 \%$ in the 1990 s and 2000-2005. East China (coastal) has made substantial technological progress and has reached a high level of technological development, as evident in the evolution of its Global Technological Development Index $\left(X_{4}\right)$, which rose from $65 \%$ in the 1980 s to $75 \%$ in the 1990s and $100 \%$ in the 2000-2012. This is hardly surprising in light of the fact that technological upgrading has been an essential ingredient of East China (coastal)'s successful economy. On the other hand, West China (inland)'s $X_{4}$ fell from $25 \%$ in the 1980 s to $15 \%$ in the 1990 s and $2000-2012$, reflecting a sharp decline in the country's technological base. This decline is both an effect and cause of the collapse of the country's poor economic performance. The large and increasing technological gap between the two countries raises the technological costs of national harmonic development.

The global development of West China (inland) and East China (coastal) in the political, social, economic and technological spheres during the 1980s, 1990s and 20002012; It clearly shows an unmistakable difference between the two Chinas. While East China (coastal) had achieved substantial progress in all four spheres, West China (inland) has failed to do so in any of the four spheres. The wide and growing inter-China gap is not limited to economic development but extends to development in other areas as well. The fact that the Chinas are becoming less similar in all aspects rather than more similar does not bode well for their national harmonic development.

We now use the four Global Development Indices $\left(X_{i}\right)$ to estimate the Global Overall Development Index (X) for the two Chinas in the 1980s and 1990s. To repeat, the Global Overall Development Index (X) measures a country's overall level of development from a multidimensional perspective encompassing the political, social, economic and technological aspects. As described earlier for the 1980s, we sum up the four triangular areas between the axes to compute $X$. We find $X$ to be $55 \%$ for East China (coastal) and $5 \%$ for West China (inland) in the 1980s, and 85\% for East China (coastal) and 5\% for West China (inland) in the 1990s. The evolution of X over time confirms the picture of a wide and growing gap between the Chinas. East China (coastal) has managed to reach a high overall development level through rapid progress in all four areas whereas West China (inland)'s overall development level continues to stagnate at a very low level. 
We use the four Global Development Indices $\left(X_{i}\right)$ and coefficients reflecting the relative importance of each Xi to measure the Global Development Stage (Y) of East China (coastal) and West China (inland) in the 1980s and 1990s. To repeat, the Global Development Stage $(Y)$ is similar to the Global Overall Development Index $(X)$ in the sense that both reflect a country's overall development level. Assuming that each coefficient is 0.25 , so that the political, social, economic and technological dimensions are equally important, we compute the Global Development Stage (Y) for East China (coastal) and West China (inland) to be 75\% and 15\%, respectively, in the 1980s. Our computed value of $Y$ rises to $95 \%$ for East China (coastal) but falls even further to $10 \%$ for West China (inland) in the 1990s. According to our earlier definitions, East China (coastal) is well into the developed stage while West China (inland) remains at a very low stage of development. The large and growing difference in $Y$ between the two Chinas mirrors the large and growing difference in their overall development level.

\section{Concluding Remarks}

We can find a large gap between East and West China (inland) is inherently a complex and multidimensional phenomenal entailing the national development of China of their economies, political systems, social systems, and a wide range of other societal hardware and software. In this paper, we looked at the prospects for China's development harmonization by comparing its development from a multidimensional perspective rather than focusing solely on any single dimension. While the growing economic gap between prosperous East China (coastal) and impoverished West China (inland) clearly increases the costs of a general development of China, a more comprehensive comparative analysis of the two Chinas calls for comparing their overall development rather than solely their economic development. To carry out such a broader analysis, we use the Global Dimension of Regional Integration Model (DGD Model) recently developed by Ruiz (2004), which evaluates the prospects for regional development from a global or multidimensional perspective. Our main finding is a large and growing gap between the two Chinas in terms of political, social, economic and technological development. East China (coastal) has achieved sustained progress in all four areas and a high level of overall development. In stark contrast, West China (inland) has failed to make progress in any of the four areas and remains mired in a very low level of overall development. Our analysis clearly reveals a divergence between the two Chinas rather than a convergence. This suggests that China's development strategy needs to improve more based on development expansion policies such as more open domestic market and easy mobility of domestic investment.

\section{Selected Sources}

Green-Peace, General Information and Database Statistics, 2004, http:/ / www.greenpeace. org. html.

Haya-Court, General Information and Database Statistics, 2004, http://www.wpc-in. org. html.

Human Rights Watch, General Information and Database Statistics, 2004, http::/ / www. hrw.org. html. 
Inter-American Development Bank, General Information and Database Statistics, 2004, http://www.iadb.org. html.

International Federation of Production Rights Organization, General Information and Database Statistics, , 2004, http:/ / www.ifrro.org. html.

International Monetary Found, General Information and Database Statistic, 2004, http:/ / www.imf.org. html.

NATO, General Information and Database Statistics , 2004, http:/ / www.nato.int. html.

Oil Producers Organization (OPEC), General Information and database statistics. http:/ / www.opec.org. html.

The Federal Reserves System, General Information and Database Statistics, 2004, http:/ / www.federalreserve.gov/pf/pf.html

The Library of Congress U.S., General Information and Database Statistics , 2004, http:/ / www.loc.gov. html.

Transparency International, General Information and Database Statistics , 2004, http:/ / www.transparency.org. html.

United Nations, General Information and Database Statistics , 2004, http://www. un.org. html.

United Nations, "Human Development Report 2004 U.N. Development Program", http:/ /hdr.undp.org/reports/General/2004/

World Bank, General Information and Database Statistics, 2004, http://www.wb.org. html.

World Health Organization, General Information and Database Statistics, 2004, http:/ / www.who.int. html.

The Federal Reserves System, General Information and Database Statistics , 2004, http:/ / www.federalreserve.gov/pf/pf.html

The Library of Congress U.S., General Information and Database Statistics, 2004, http:/ / www.loc.gov. html.

Transparency International, General Information and Database Statistics , 2004, http:/ / www.transparency.org. html.

United Nations, General Information and Database Statistics, 2004, http:/ / www.un.org. html.

World Bank, General Information and Database Statistics, 2004, http://www.wb.org. html.

World Health Organization, General Information and Database Statistics, 2004, http:/ / www.who.int. html. 